\title{
Morphological Observation of Interaction between PAMAM Dendrimer Modified SWCNT and Pancreatic Cancer Cells
}

\author{
Dongfeng Chen ${ }^{1 *}$, Xubo $\mathrm{Wu}^{1}$, Jiaxiang Wang ${ }^{1}$, Baosan $\mathrm{Han}^{1}$, Ping Zhu², Chenghong Peng ${ }^{1}$ \\ ${ }^{1}$ Center of the organ transplantation and Department of surgery, Shanghai Institute of Digestive Surgery, Ruijin Hospital, \\ Shanghai JiaoTong University Medical college, Shanghai 200025, China ${ }^{2}$ Electron Microscope Lab., Shanghai JiaoTong \\ University Medical college, Shanghai 200025, China
}

*Corresponding authors. E-mail: chengdf1059@163.com

\begin{abstract}
With the aim of observing morphological changes of pancreatic cancer cells transfected by PAMAM dendrimer modified single walled carbon nanotubes(SWCNT-PAMAM complexes), the SWCNT-PAMAM complexes were prepared and characterized by atom force microscopy. Then the prepared SWCNT-PAMAM complexes with different concentration such as 5, 10, 15, 20, $25 \mu \mathrm{g} / \mathrm{mL}$, were incubated with human pancreatic cancer cell line BXPC3 cells for 12 to 72 hours, the cytotoxicity of SWCNT-PAMAM complexes was investigated, cell slips were prepared and observed by transmission electron microscopy. Results showed that SWCNT-PAMAM complexes were prepared successfully, and could be transfected into human pancreatic cancer cells by the way of cell pinocytosis. With the extension of the transfecting time, rounded granular SWCNT-PAMAM complexes located not only in the cytoplasm, but also in the lysosome, as well as in the nucleus. Compared with normal control group, there existed no significant change in pancreatic cancer cell's morphology, the SWCNT-PAMAM complexes within $25 \mu \mathrm{g} / \mathrm{ml}$ did not exhibit obvious toxicity to pancreatic cancer cells. In conclusion, the prepared SWCNT-PAMAM complexes may be a low toxic, good stable vector for gene or drug delivery system.
\end{abstract}

Keywords: Pancreatic tumor cell; Single walled carbon nanotube; Polyamidoamine dendrimer; Electron microscopy; Atom force microscopy

Citation: D. Chen, et al. Morphological Observation of Interaction between PAMAM Dendrimer Modified Single Walled Carbon Nanotubes and Pancreatic Cancer Cells. Nano Biomed Eng. 2010, 2(1), 61-66. DOI:10.5101/nbe.v2i1.p61-66.

\section{Introduction}

Carbon nanotubes, as a class of stiff, stable and hollow nanomaterials with many unique properties such as mechanical, physical and chemical properties, have been being explored application in biomedical engineering and medical chemistry [1-5]. For example, carbon nanotubes have been used as AFM tip to obtain atomic-resolution imaging of the biological molecules such as DNA and proteins [6-7]. Carbon nanotubes can be filled with DNA or peptide molecules and have highly potential in gene or peptide storage and delivery system in molecular therapy of Diseases [8-9].
SWCNTs could inhibit the growth of human HEK293 cells and human fibroblast cells in dose-and timedependent means [10-11], and could induce the apoptosis of embryonic stem cells [12]; antisense oligonucleotides conjugated SWCNTs could enter into HL-60 cytoplasm and kill tumor cells [13]; dendrimermodified multiwall carbon nanotubes could deliver a lot of genes or drugs into tumor cells high-efficiently [14]. Besides, SWCNTs was reported to exhibit strong antimicrobial activity [15]; biomolecules-conjugated SWCNTs could get through BY-2 cell walls, and exhibited little toxicity to BY-2 cells [16]. Up to date, 
PAMAM dendrimers. The PAMAM-SWCNT

the dendrimer-modified carbon nanotubes has been confirmed to be one kind of high-efficient gene or drug delivery system [14], however, dendrimer-modified carbon nanotubes' biocompatibility and stability are still not clarified well.

Herein we prepared polyamidoamine dendrimer modified single-walled carbon nanotubes (SWCNTPAMAM complexes), and incubated with human pancreatic cancer cell line BXPC3 cells, and observed the morphological changes of human pancreatic cancer cell line BXPC3 cells transfected by different concentration of SWCNT-PAMAM complexes, and investigated the potential toxicity, with the aim of investigating the biosafety of polyamidoamine dendrimer modified single-walled carbon nanotubes to pancreatic cancer cell line BXPC3 cells.

\section{Materials and methods \\ 2.1 Materials}

Single-walled carbon nanotubes (SWCNTs) with 99.9\% purity were obtained from Shenzhen Nanoport Company (Shenzhen, China). Human pancreatic cancer cell lines BXPC3 were purchased from Shanghai Cell Institute, Chinese Academy of Sciences. DMEM (Gibco BRL, Gaithersburg, MD, USA) were supplemented with $10 \%$ fetal calf serum (FCS, Gibco BRL), penicillin $(100 \mathrm{U} / \mathrm{ml})$, streptomycin $(100 \mu \mathrm{g} / \mathrm{ml})$, L-glutamine $2 \mathrm{mM}$ (ICN Biomedicals, Costa Mesa, CA, USA) and amphotericin B $2.5 \mu \mathrm{g} / \mathrm{ml}$ (Sigma-Aldrich). Culture medium contains $10 \%$ fetal bovine serum with RPMI1640 culture medium, the pancreatic cancer cells were cultured under the conditions of $37{ }^{\circ} \mathrm{C}, 5 \% \mathrm{CO}_{2}$. Polyamidoamine (PAMAM) dendrimer was provided by prof. Daxiang Cui in Institute of Micro-Nano Science and Technology of Shanghai Jiao Tong University.

\subsection{Svnthesis of PAMAM dendrimer- modified SWCNTs}

Synthesis of PAMAM dendrimer-modified SWCNTs was finished according to our previous reports $[14,17]$. The main procedure is as follows: 0.1 $\mathrm{mg}$ SWCNTs were dispersed in $5 \mathrm{ml} \mathrm{H}_{2} \mathrm{SO} 4 / \mathrm{HNO}_{3}$ (3:1) mixture, treated by ultrasonic bath for 5 hours at room temperature, and stirred for 24 hours. The filtration was done to remove the mixed acid. After centrifugal and washing with distilled water three times, the carbon nanotubes were dispersed into $2.0 \mathrm{ml}$ distilled water, and then placed into autoclave at $120{ }^{\circ} \mathrm{C}$ for 25 minutes. The carbon nanotubes were mixed with $1.0 \mathrm{ml} \mathrm{No.4}$ generation of PAMAM dendrimer aqueous solution $(1 \mathrm{mmol} / \mathrm{L})$. The mixture was treated by ultrasonic waves for 2 hours and then stirred for 24 hours at room temperature. The filtration was done by using $0.22 \mathrm{um}$ millipore polycarbonate membrane and subsequently washed three times to remove superfluous complexes were dried, and diluted into different concentration.

\subsection{Characterization of SWCNT-PAMAM complexes}

The SWCNTs, PAMAM dendrimer and SWCNTPAMAM complexes were dripped on the surface of mica. After natural dry, the complexes were observed by atomic force microscope (AFM). While part of the complexes were added to the copper mesh surface. After natural dry, the complexes were observed by transmission electrical microscopy (TEM).

\subsection{Observation of SWCNT-PAMAM complexes in pancreatic cancer cells}

Pancreatic cancer cells were collected and adjusted to the cell density of $2 \times 10^{5} / \mathrm{L}$. After cells were cultured for 6 hours at $37^{\circ} \mathrm{C}, 5 \% \mathrm{CO}_{2}$. the cell adhesion was up to $50 \%-60 \%$, equivalent $(300 \mu \mathrm{l})$ of SWCNTPAMAM complexes were added into the culture dishes according to the following groups and time points. There are two groups: test group, $300 \mu 1$ of SWCNTPAMAM complexes were added into each cell culture dishes; the control group: the same amount of normal saline $(300 \mu \mathrm{l})$ was added into the control cell culture dishes. These cells were incubated under the condition at $37^{\circ} \mathrm{C}, 5 \% \mathrm{CO}_{2}$ Forma. At the time points of 12,24 , 36,48 , and 72 hours, growth of cells was observed by the laser confocal microscope. At each time point, the cells in one of all the culture dishes were collected, fixed with both $2.5 \%$ glutaral- dehyde and $1 \%$ osmium tetroxide, embedded by Spurr embedding medium and then sliced by LKB ultramicrotome. The cell ultrastructures were observed under transmission electron microscope.

\subsection{Cytotoxicity of SWCNT-PAMAM complexes}

The Cell Counting Kit-8 assay (Dojindo Laboratories) was used to measure cytotoxicity of synthesized nanoprobes following the instruction of the kit. Pancreatic cancer cells incubated with and without SWCNT-PAMAM complexes were cultured under the condition at $37{ }^{\circ} \mathrm{C}$ and $5 \% \mathrm{CO}_{2}$ for 12 to 72 hours, the cell viability was tested by both $0.4 \%$ trypan blue and Calcein-AM staining [18].

\section{Results}

\subsection{Characterization of SWCNT-PAMAM complex}

As shown in Figure 1A, single walled carbon nanotubes exhibited good dispersion, very clear, their lengths were controlled within $50 \mathrm{~nm}$. Figure 1B 


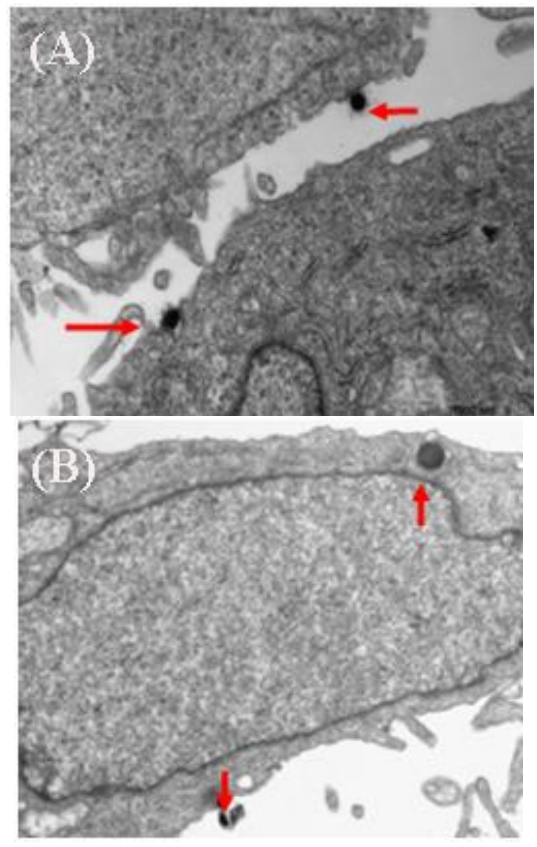

showed the image of PAMAM dendrimer molecules, Figure 1C showed the image of prepared PAMAM dendrimer modified single-walled carbon nanotubes, which clearly confirmed the SWCNT-PAMAM complexes were successfully prepared.

\subsection{Dynamic observation of SWCNT-}

PAMAM complexes in pancreatic cancer cell

We used TEM to observe the samples of pancreatic cancer cells incubated with $20 \mathrm{ug} / \mathrm{ml}$ SWCNTPAMAM complexes for $12 \mathrm{~h}, 24 \mathrm{~h}, 36 \mathrm{~h}$ and $72 \mathrm{~h}$. Figure 2 (2A-2B arrows) highly suggest that the cell pinocytosis maybe the main way of the pancreatic cancer cells capturing SWCNT-PAMAM complexes.

12 hours after SWCNT-PAMAM complexes being transfected into human pancreatic cancer cells as shown in Figure 3, the cytoplastic organelles and nuclear membrane are integral. The nuclear chromosomes distribute evenly. The structure of mitochondrial is also intact, cytopla- smic inclusions are abundant. Some dark black dots distribute around rough endoplasmic reticulum. The morphology of cells is normal.

After 36 hours co-culture, CNT-PAMAM complexes locate not only in the cytoplasm, but also in the nucleus as shown in Figure 4. After 72 hours co-culture, the cytoplastic organelles and nuclear membrane are still integral, as well as the structure of the mitochondrial. There are some lysosomal remnants. Some vacuoles containing darker small particles appear in the cytoplasm as shown in Figure 5A-5B. Cell morphology is still intact and shows the same as that of control group, which indicates that CNT-PAMAM complexes have no significant damage to the cells.

\subsection{Cytotoxicity of SWCNT-PAMAM complexes}

As indicated in Figure 6, treatment of pancreatic cancer cells with various concentrations $(5 \mu \mathrm{g} / \mathrm{ml}, 10$ $\mu \mathrm{g} / \mathrm{ml}, 15 \mu \mathrm{g} / \mathrm{ml}, 20 \mu \mathrm{g} / \mathrm{ml}, 25 \mu \mathrm{g} / \mathrm{ml}, 0 \mu \mathrm{g} / \mathrm{ml}$ control) of SWCNT-PAMAM complexes did not cause a marked time- and dose-dependent decrease in cell viability relative to the control culture, which showed that the SWCNT-PAMAM complexes did not exhibit marked toxicity to pancreatic cancer cells.

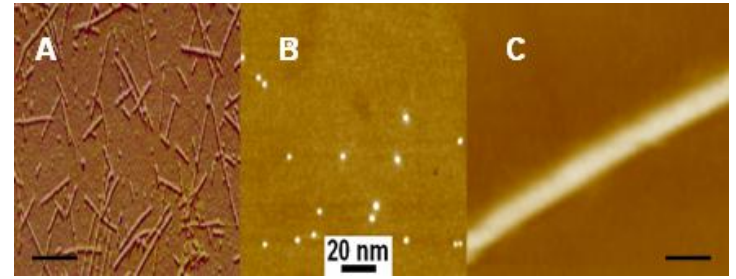

Figure 1. AFM Images of single walled carbon nanotubes, dendrimer molecules and PAMAMSWCNTs complexes. A: image of SWCNTs, bar 20nm; $\mathrm{B}$ : image of G4 PAMAM dendrimer molecules; C: image of PAMAM-SWCNT complexes, bar: $20 \mathrm{~nm}$.
Figure 2. CNT-PAMAM complex closed to the cell membrane and was captured (arrows). 17,000 times (A) and CNT-PAMAM complex was obtained by pinocytosis (arrows). 33,000 times (B)

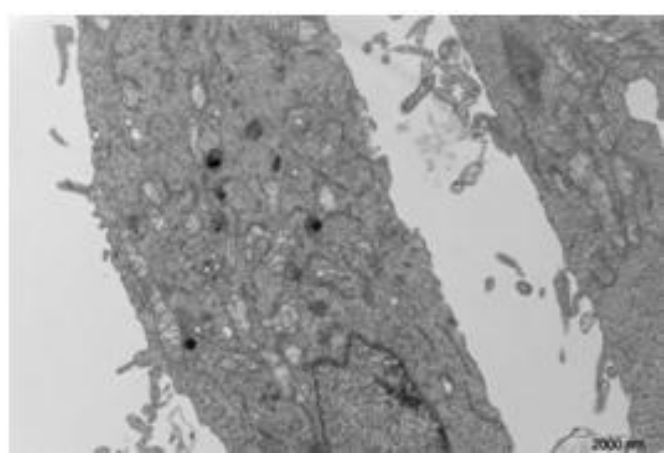

Figure 3. After 12 hours co-culture, CNT-PAMAM complexes mainly locate in the cytoplasm, some are engulfed by the lysosome. 9,700 times

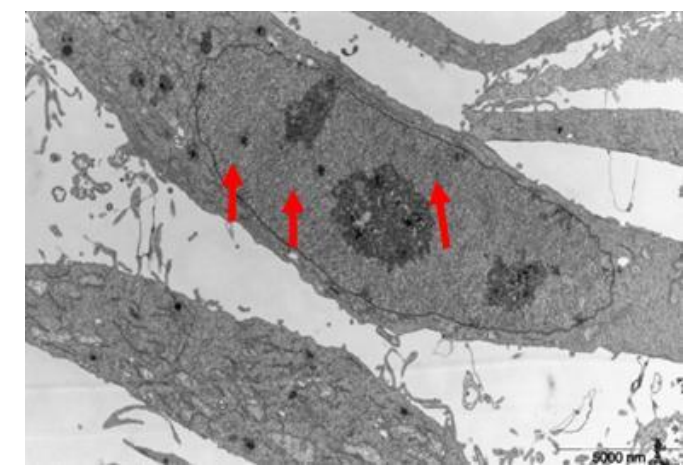

Figure 4. After 36 hours co-culture, CNT-PAMAM complexes locate not only in the cytoplasm, but also in the nucleus (arrows). 5,800 times 

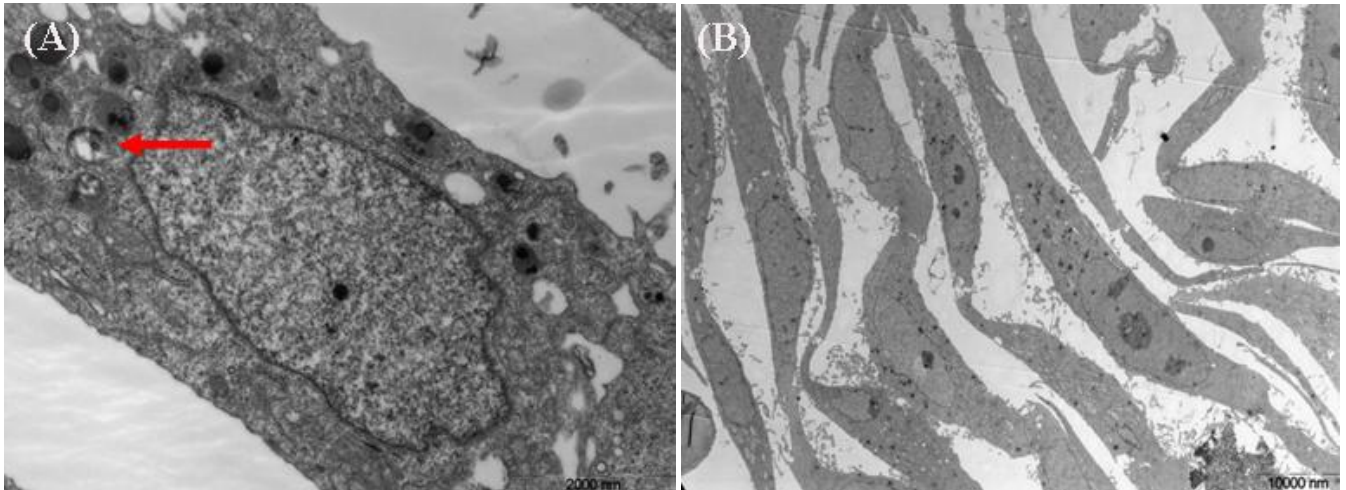

Figure 5. After 72 hours co-culture, there are some lysosomal remnants. Some vacuoles containing darker small particles appear in the cytoplasm (arrows). 17,500 times (A), After 72 hours co-culture, cell morphology is still intact the same as that of the control group. 1,850 times (B)

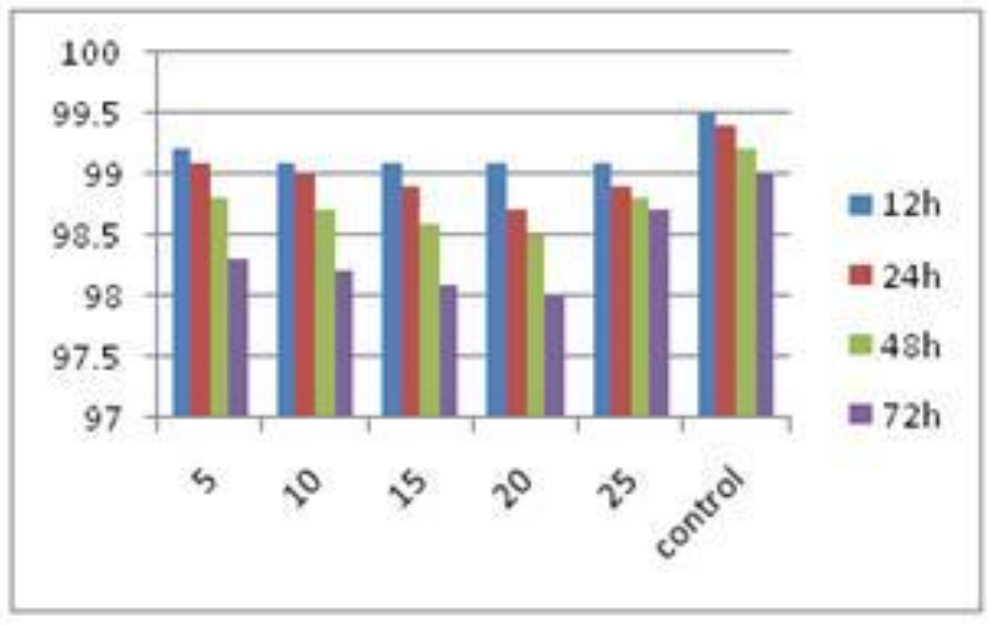

Figure 6. Effects of SWCNT-PAMAM complexes on viability of pancreatic cancer cells X axis: $\mu \mathrm{g} / \mathrm{ml}, \mathrm{Y}$ axis, cell viability $(\%)$.

\section{Discussion}

The development of nanotechnology has brought new opportunities in treatment of cancer [19-21]. The purpose of gene therapy is gene targeting transduction to the tumor cells and tissues for further expressions. Therefore the choice of delivery vector is one of the keys for gene therapy. There exists low transfection efficiency, immunogenicity and potential tumorigenicity in the traditional delivery vectors for gene therapy such as viral vectors, etc. For the security and other reasons, these traditionally gene therapies have been exploredly used for clinical therapy [22-23]. Development of non-toxic and efficient gene delivery vector has been more and more taken into attention. Development of non-toxic and efficient gene delivery vector and increasing gene transfection efficiency has become currently main challenges in gene therapy [24]. Whether the carrier on delivery of genes could be engulfed by the cell, and whether the foreign genes could be protected from degradation by varieties of nucleases are depended on the physical and chemical properties of the gene vector. In recent years, nanocarriers have been regarded as one of the most promising technology on breakthrough the bottleneck of gene transfer [25-26]. However, nano-carriers' biosafety has caused great attention from scientists from different area, and has become a hotspot [27-29].

Carbon nanotubes are one class of high hardness, stability and hollow one-dimensionally nanomaterials. Molecular dynamics simulations and experiments have confirmed that carbon nanotubes can carry nucleic acid or protein molecules quickly and freely into the cytoplasm and the nucleus. They are potential gene delivery vector [30]. However, carbon nanotubes contain some metal catalysts, such as iron, nickel, etc. These substances in cells could trigger redox reaction to generate hydrogen peroxide, free radicals and other active oxygen, which can damage DNA and further cause damage to the cells [30]. Soto's studies have shown MWNTs' toxicity to mouse macrophage [30]. Cui's experiments show that cells' adhesion 
performance will be severely affected after cells' treatment by carbon nanotubes [10-11]. Then, cell walls appear off, suspend and crimple. Carbon nanotubes can also increase expressions of apoptosisrelated genes such as P16 and P53 so that cells are arrested in Gl phase and lead to apoptosis eventually [10]. Some reports also showed that biomolecules modified carbon nanotubes can improve the biocompatibility of carbon nanotubes [30].

Polyamidomine dendrimers are recognized as synthetic, highly branched, spherical, single-particle and dispersive nano- molecules, are a relatively novel class of cationic polymers. Their structural parameters such as size, shape and surface chemistry can be completely controlled during the course of synthesis [31]. In physiological conditions, these PAMAM dendrimers enter into the cytoplasm by endocytosis, after the interaction takes place between their surface cationic amine group Kiki with positive charges and glycoprotein and phospholipids with negative charges in cell membrane. Dendrimers can also induce lipid bilayer appear nanopores so as to enhance transfection efficiency [32-33]. PAMAM-DNA complexes can pass through a variety of biological barriers such as the reticuloendothelial system and the blood-brain barrier and reach to the specific site [33-34]. Vitro and vivo experiments show that PAMAM dendrimers have small size and high zeta potential than any other cation carrier, and enter into cells more conductively by the way of endocytosis and pinocytosis with good biocompatibility and no immunogenicity $[18,26,29]$. After carbon nanotubes modified with PAMAM dendrimers, the DNA can be effectively protect from nuclease degradation by electrostatic interaction as results of reducing the cytotoxicity of CNTs $[22,24,30]$, so PAMAM dendrimer is considered as the better gene delivery vector. Therefore, the complexes of carbon nanotubes and PAMAM dendrimer assembled together should be regarded as a very promising, safe and efficient gene delivery vector.

In this study, we used TEM to observe the dynamic morphological changes of pancreatic cancer cells transfected by SWCNT-PAMAM complexes. Results showed that cell pinocytosis may be the main way of the pancreatic cancer cells capturing SWCNTPAMAM complexes. With the extension of the transfecting time, rounded granular SWCNT-PAMAM complexes located not only in the cytoplasm, but also in the lysosome, and in the nucleus. Compared with the control group, pancreatic cancer cells transfected with SWCNT-PAMAM complexes remain healthy, appear no significant change in morphology and show good stability, which indicate that SWCNT-PAMAM complexes within $25 \mu \mathrm{g} / \mathrm{ml}$ usage concentration did not display the obvious damage to pancreatic cancer cells, for example, cell apoptosis, etc. For cell transfected experiments, SWCNT-PAMAM complexes within 25 $\mu \mathrm{g} / \mathrm{ml}$ usage concentration is enough to deliver a lot of gene into pancreatic cancer cells, therefore, we consider that the SWCNT-PAMAM complexes should be a safe vector for gene delivery. Although further molecular level changes in pancreatic cancer cells transfected by SWCNT-PAMAM complexes are not still investigated well, we believe that the SWCNTPAMAM complex should be an ideal in vivo gene delivery vector, and has great potential in applications such as cancer molecular imaging and therapy.

\section{Acknowledgement}

This research was supported by Shanghai Municipal Science and Technology Fund (No.09140902300), and National Natural Science Foundation (No.30772105). Authors also appreciate Prof. Daxiang Cui for critical review and a lot of help in experiments. The authors thank the Instrumental Analysis Center of Shanghai Jiao Tong University for the Materials Characterization.

\section{References}

1. Baughman RH, Zakhidov AA, Heer DA. Carbon nanotubes-the route toward applications. Science 2002; 297: 787-792. doi:10.1126/science.1060928

2. Bianco A, Prato M. Can carbon nanotubes be considered useful tools for biological applications? Adv Mater 2003; 15: 1765-1766. doi:10.1002/adma.200301646

3. Pantarotto D, Briand JP, Prato M, Bianco A. Translocation of bioactive peptides across cell membranes by carbon nanotubes. Chem Commun 2004; 1: 16-17. doi:10.1039/ $\underline{\mathrm{b} 311254 \mathrm{c}}$

4. Cui D, Pan B, Zhang H, Gao F, Wu R, Wang J, et al. Selfassembly of quantum dots and carbon nanotubes for ultrasensitive DNA and antigen detction. Anal Chem 2008; 80(21): 7996-8001. doi:10.1021/ac800992m

5. Xu P, Cui D, Pan B, Gao F, Rong H, Li Q, et al. A facile strategy for covalent binding of nanoparticles onto carbon nanotubes. Appl Surf Sci 2008; 254: 5236-5240. doi:10.10 16/j.apsusc.2008.02.082

6. Nagao E, Nishijima H, Akita S, Nakayama Y, Dvorak J.A The cell biological application of carbon nanotube probes for atomic force microscopy: comparative studies of malariainfected erythrocytes. $J$ Electron Microsc (Tokyo) 2000; 49: 453-458.

7. Hafner J.H., Cheung C.L.,Woolley A.T., Lieber C.M., Structural and functional imaging with carbon nanotube AFM probes. Prog Biophys Mo. Bio. 2001; 77: 73-110. doi:10.1016/S0079-6107(01)00011-6

8. Gao H., KongY., Cui D, Ozkan C.S. Spontaneous insertion of DNA oligonucleotides into carbon nanotubes. Nano. Lett. 2003; 3: 471-473.

9. Cui D, Ozkan C.S., Ravindran S., KongY, Gao H. Encapsulation of Pt-labelled DNA molecules inside carbon nanotubes. Mech. Chem. Biosystems 2004; 1: 113-121. doi: $\underline{10.1021 / \mathrm{n} 1025967 \mathrm{a}}$

10. Cui D, Tian F, Ozkan C, Wang M, Gao H. Effect of single wall carbon nanotubes on human HEK293 cells. Toxicol Lett 2005;155(1):77-83. doi:10.1016/j.toxlet.2004.08.015

11. Tian F, Cui D, Schwarz H, Estrada GG, Kobayashi H. 
Mooney DJ. Non-viral gene delivery regulated by stiffness of cell adhesion substrates. Nat Mater. 2005 ;4(6):460-4. Epub 2005 May 15. doi:10.1038/nmat1392

24. Majoros IJ, Thomas TP, Mehta CB, Baker JR. Poly (amidoamine) dendrimer-based multifunctional engineered nanodevice for cancer therapy. $J$ Med Chem, 2005; 48(19):5892-5899. doi:10.1021/jm0401863

25. Najlah M. D'Emanuele A.Crossing cellular barriers using dendrimer nanotechnologies. Curr Opin Pharmacol, 2006; 6(5): 522-527.

26. Cheng Y, Wang J, Rao T, He X, Xu T. Pharmace utical applications of dendrimers: promising nanocarriers for drug delivery. Front Biosci 2008; 13: 1447-1471.

27. Cui D. NanoToxicology. Zhao Y.L. and Nalwa H. S., editor-in-chief, American Scientific Publisher, 2007:103111.

28. Zhang $\mathrm{X}$, Wang $\mathrm{X}, \mathrm{Lu} \mathrm{Q}, \mathrm{Fu} \mathrm{C}$. Influence of carbon nanotube staffolds on human cervical carcinoma HeLa cell viability and focal adhesion kinase expression. Carbon 2008; 46: 453-60. doi:10.1016/j.carbon.2007.12.015

29. Worle-Knirsch JM, Pulskamp K, Krug HF. Oops they did it again! Carbon nanotubes hoax scientists in viability assays. Nano Lett 2006; 6:1261-68.doi:10.1021/n1060177c

30. Cui D. Advance and prospects of biomolecules functionnalized carbon nanotubes. J Nanosci Nanotechnol 2007; 7(4-5): 1298-1314. doi:10.1166/jnn.2007.654

31. Duncan R, Izzo L. Dendrimer biocompatibility and toxicity. Adv Drug Deliv Rev, 2005; 57(15): 2215-2237. doi:10.1016/j.addr.2005.09.019

32. Kitchen KM. El-Sayed ME. Ghandehari H. Transepithelial and endothelial transport of poly (amidoamine) dendrimers. Adv Drug Deliv Rev, 2005; 57(15): 2163-2176. doi:10.1016/j.addr.2005.09.013

33. Majoros U, Thomas TP, Mehta GB, et al. Poly (amidoamine) dendrimer-based multifunctional engineered nanodevice for cancer therapy. J Med Chem. 2005; 48(19): 5892-5899. doi:10.1021/jm0401863

34. Pan B, Cui D, Sheng Y, Gao F, He R, Li Q, et al. Dendrimer-modified magnetic nanoparticles enhance efficiency of gene delivery system. Cancer Research. 2007; 67(17):8156-8163. doi:10.1158/0008-5472.CAN-06-4762

\section{Received 23 February, 2010; accepted 7 March, 2010;} published online 8 March, 2010.

Copyright: (c) 2010. D. Chen et al. This is an open-access article distributed under the terms of the Creative Commons Attribution License, which permits unrestricted use, distribution, and reproduction in any medium, provided the original author and source are credited. 